Giovanelli, in a valuable theoretical discussion of flare formation ${ }^{24}$, bases his electromagnetic ideas upon the development of induced electric fields in the vicinity of sunspots during the periods of most rapid growth and decay of the spot magnetic fields. At critical values of the electric field which he has calculated, he shows that electrons may gain energy from the field more rapidly than it can be dissipated in atomic collisions. Under such conditions, something analogous to a gigantic lightning flash takes place in the sunspot region. It may be said that there is a great deal of observational evidence in support of the mechanism which he proposes, though there are still many detailed aspects which await explanation.

Discussing the origin of the radio-frequency radiation from the galaxy, Unsöld ${ }^{25}$ deduces that this must originate in stars of late type which show flare activity like the sun, only on a scale $10^{11}$ times as great. Assuming that such stars exist-and there are many features of the emission lines of $M$-type variables which are similar to solar flare spectra-he develops the hypothesis that cosmic radiation as a whole is the smoothed result of high-energy particle emissions from the flare mechanisms which are continuously and extensively active in the atmospheres of these stellar sources.

${ }^{1}$ Hale, G. E., Astrophys. $J ., ~ 73,379$ (1931).

${ }^{2}$ Richardson, R. S., and Minkowski, R., Astrophys. J., 89, 347 (1938).

${ }^{3}$ Allen, C. W., Mon. Not. Roy. Ast. Soc., 100, 635 (1940).

'Ellison, M. A., Mon. Not. Roy. Ast. Soc., 106, 500 (1946).

${ }^{5}$ Ellison, M. A., Mon. Not. Roy. Ast. Soc., 109 (in the press).

- Ellison, M. A., and Hoyle, F., The Observatory, 67, 181 (1947).

'Durand, Oberly and Tousey, Astrophys. J., 109, 1 (1949).

${ }^{8}$ Hey, J. S., Parsons, S. J., and Phillips, J. W., Mon. Not. Roy. Ast. Soc., 108, 354 (1948). Newton, H. W., Mon. Not. Roy. Ast. Soc., Geophys. Supp., 5, 159

${ }^{10}$ McNish, C. R., Terr. Mag., 42, 109 (1937).

${ }^{11}$ Dellinger, J. H., Terr. Mag., 42, 49 (1937).

${ }^{12}$ Chapman, S., and Price, W. C., Phys. Soc., Rep. Prog. Phys., 3, 61 (1937).

${ }^{13}$ Bracewell, R. N., and Straker, T. W., Mon. Not. Roy. Ast. Soe., 109 (in the press).

${ }^{14}$ Chapman, S., and Ferraro, V. C. A., Terr. Mag., 38-38 (1931-33).

${ }^{15}$ Newton, H. W., Mon. Not. Roy. Ast. Soc., 103, 244 (1944).

is Wulf, O., and Nicholson, S. B., Proc. Ast. Soc. Pacific, 60, 37 (1948).

${ }^{17}$ Richardson, R. S., Annual Report Mount Wilson Obs., 1943-44.

${ }^{18}$ Brück, H., and Ruttlant, F., Mon. Not. Roy. Ast. Soc., 108, 130 (1946)

${ }^{10}$ Kahn, F. D., Mon. Not. Roy. Ast. Soc., 109 (in the press)

${ }^{20}$ Newton, H. W., Mon. Not. Roy. Ast. Soc., 102, 2 (1942).

${ }^{21}$ Ellison, M. A., Mon. Not. Roy. Ast. Soc., 102, 11 (1942).

${ }^{22}$ Forbush, S. E., Phys. Rev., 70, 771 (1946).

s Ehmert, A., Z. Naturf., 3a, 264 (1948).

"Giovanelli, R. G., Mon. Not. Roy. Ast. Soc., 108, 164 (1948)

${ }^{25}$ Unsöld, A., Nature, 163, 489 (1949).

$$
63 / 2
$$

\section{SCIENTIFIC INSTRUMENTS AND APPARATUS}

\section{PHYSICAL SOCIETY'S ANNUAL EXHIBITION \\ $\mathrm{N}$ his presidential adpross to \\ $\mathrm{N}$ his presidential adpows to the British Association} 1 at Brighton in September last, Sir Henry Tizard said, ". . it Pnot the general expansion of research in this cher that is of first importance for thefrestontion of $\$$ lindustrial health, and certaing rot the expansion of government research remote from the everyday problems of industry. . . . What is of first importance is to apply what is already known." In general, knowledge in the physical sciences, he remarked, now accumulates much faster than it can possibly be applied to industry. No new discovery, in any field, is likely to have so quick and beneficial an effect on British industry as the application of what is already known.

This point of view finds support in the Annual Exhibition of Scientific Instruments organised by the Physical Society. The thirty-third exhibition of this character was held at the Imperial College of Science and Technology, South Kensington, during April 5-8. It was formally opened by Prof. G. I. Finch, president of the Physical Society and chairman of the Exhibition Committee. On this occasion more than a hundred and fifty firms, research sections of government departments and trade associations were showing examples of recent developments in the design and production of scientific instruments and new techniques applying physical principles. As the president of the Physical Society pointed out, "The object of the Physical Society is to promote the growth and diffusion of a knowledge of Physics, and the Annual Exhibition, with its accompanying discourses and films, is one of the Society's activities directed towards this end".

Unfortunately, owing to structural alterations now proceeding at the Imperial College, it was necessary this year to reduce the space available for the Exhibition by about 30 per cent, which necessitated reducing the number of exhibits by roughly that proportion. An interesting departure from previous exhibition arrangements was to abolish the line of demarcation between "Trade" and "Research" exhibits. The number of visitors attending the Exhibition this year was about the same as last year, reaching a total of about 13,000. As before, the issue of tickets was restricted to avoid overcrowding.

On three occasions during the Exhibition, the film of the "Teleidoscope" or "Liquid Eidophor" was shown. The film demonstrates a recent development in cinema television equipment. The teleidoscope, developed under the direction of the late Prof. F. Fischer at the Federal Technical Highschool, Zurich, employs a novel means of picture production depending on the effects of electro-capillarity. A modulated cathode ray beam scans a raster upon a uniform liquid layer, the so-called 'eidophor', spread upon a revolving glass disk. Each point of the raster takes the form of a minute lens the curvature of which depends on the instantaneous charge impressed by the scanning beam upon the corresponding area of the eidophor liquid. The raster is resolved into a visible image using a Töpler schlieren system. The potential advantage of this system over the conventional cathode ray tube depends on the fact that it constitutes a true light valve, the light output of which is independent of the energy of the cathode ray scanning beam, an advantage which possesses great flexibility. The degree of picture 'storage' achieved by this system can be varied by appropriately adjusting the rate of leakage of the charges on the eidophor in such a way that the raster remains sensibly unchanged for the duration of each frame and is then electrically wiped out by the conductivity of the eidophor.

Three discourses were given during the Exhibition. The first of these, by Dr. J. A. Radcliffe, of the Cavendish Laboratory, Cambridge, was concerned with "Some Problems of Wave Diffraction in the Ionosphere". Simultaneous observations of radio 
'fading' at two points indicate that radio waves are returned from the ionosphere by a process of diffractive reflexion as if from a rough surface. The diffraction effects produced by a simple model of this kind can be related to well-known phenomena of optical diffraction. Dr. Radcliffe showed that the methods of calculation are similar to those employed in the analysis of random fluctuations such as occur with radio 'noise'. The fading was shown to be produced by movements of the random irregularities in the ionosphere and is related to their turbulent or regular motions. It was shown how winds in the ionosphere can be measured, and how some of the observed radio effects are similar to well-known optical phenomena.

In the second discourse, Mr. A. J. Philpot, of the British Scientific Instrument Research Association, dealt with "Some Modern Aspects of Scientific Instruments". He directed attention to the fact that three factors have markedly affected the design of scientific instruments in recent years. In the first place, the field of use of instruments has greatly increased and extends to almost every sphere of human activity. The environment of the scientific instrument is no longer exclusively in the laboratory, and instruments of great precision are now to be found in everyday use in workshop and factory. In the second place, the users of instruments are no longer a specialist class, and only a small proportion are scientific workers. In these days of instrumentation, lay users of instruments probably outnumber the scientific users. Lastly, advances in science and the emergence of new branches of science, notably that of electronics, have given to the instrument designer new aids in the achievement of his purposes. Modern scientific instruments incorporate features which reflect these changing circumstances and take advantage of new techniques.

The third discourse, given by Prof. O. R. Frisch, of the Cavendish Laboratory, Cambridge, gave "A Review of the Miethods and Instruments used in Energy Measurements on Particles emitted from Atomic Nuclei". A short discussion of the general phenomena of ionization and excitation of atoms, on which the detection of nuclear fragments is based, was followed by a description of ionization chambers, proportional and Geiger-Miüller counters, liquid and crystal counters, and scintillation counters, together with a discussion of their respective merits, and of their suitability for energy measurement. Magnetic and electric deflector methods were considered also, in conjunction both with counters and with cloud chambers. Auxiliary equipment such as coincidence circuits, scalers, kick-sorters, etc., were briefly described.

The wide diversity of the exhibits is indicated in the "Handbook of Scientific Instruments and Apparatus 1949", containing more than 270 pages of descriptive matter and some sixty pages of trade advertisements. This handbook, which is well printed and illustrated on high-quality paper, forms not only a guide to the exhibits but also serves, as its title indicates, as a handbook of reference to present British achievements in scientific instrument design and manufacture. A visitor to the Exhibition was impressed not only by the wide diversity and novelty of many exhibits in electronics and atomic physics, for example, but also by the excellence and high quality in the design and construction of the more ordinary, or more familiar, types of scientific instruments. The latter are exemplified by a wide range of electrical measuring instruments, galvanometers, electrical bridges and test sets, resistors, voltage stabilizers, valve oscillators, recorders, colorimeters, densitometers, microscopes, photometers, photocells, spectrometers, ultrasonic oscillators, X-ray equipment and so on. While most of these are based on well-known physical principles, almost all of them embody up-to-date improvements in important details which make them more serviceable and reliable in the laboratory and workshop. In an age of electronics and atom physics, one is apt to overlook, for example, the importance of such an old friend as the laboratory balance; but the aperiodic balance of to-day is remarkable evidence of progress and is proof of the beauty and excellence of British instrument design and craftsmanship. A microchemical balance with a load capacity of $20 \mathrm{gm}$., a sensitivity of $0.001 \mathrm{mgm}$. $(0.1 \mathrm{mgm}$. swings the pointer 100 scale divisions), and a short period of oscillation is a very fine achievement. The weightchanging mechanism of modern balances is a great improvement on the old method employing tweezers and a box of weights. Other interesting exhibits of a mechanical nature include an apparatus for producing and measuring accelerations of the order of $10^{4}-10^{5} \mathrm{~g}$; the measurement of the mechanical properties (hardness, work-hardening, elasticity and crumbliness) of cheese, these properties being related to the subjective judgment of cheese 'body' by experts ; the 'sine' spring, a new mechanical device having a blade spring shaped like a sine curve, the stiffness of which can be varied continuously from positive through zero to negative values.

On the optical side, an interesting exhibit showed a low-power stereoscopic binocular microscope for use by aural surgeons while performing the fenestration operation. The illuminating system is duplicated so there is no risk of a breakdown during an operation. An optical device for metering the size of particles dispersed in a liquid uses a flat beam of light which, after passing through a layer of the dispersion, falls on a photo-cell and deflects a galvanometer. This gives a continuous indication of the extinction coefficient of the suspension at the sampling depth, from which the particle-size distribution can be calculated. Two very good types of double-beam infra-red spectrometer were demonstrated, giving a direct record of percentage transmission as a function of wave-length. The Physical Society Optical Group provided a popular exhibit of curiosities in colour vision, demonstrating Benham's top, Bidwell's ghost and other phenomena associated with colour and the eye. Some very fine examples of electron microscopes were demonstrated, giving magnifications of the order 10,000-100,000 times. These beautiful instruments are now robust and simple to manipulate. Lead selenide cells were shown, capable of covering a range up to $5 \mu$ at liquid-air temperature. A very impressive demonstration was staged by the National Physical Laboratory, using the isotopic mercury lamp, presented to the N.P.L. by the National Bureau of Standards, Washington. The lamp is an electrode. less tube containing pure argon at $3-\mathrm{mm}$. pressure and $3 \mathrm{mgm}$. of the isotope mercury 198 , produced by neutron irradiation of pure gold. The little globules of this mercury isotope could be seen clearly in the tube. The extremely monochromatic quality of the radiation from the tube made it suitable for the direct measurement of end standards up to $40 \mathrm{~cm}$. length. In acoustics, a low-frequency analyser, developed to the requirements of the Royal Aircraft 
Establishment, Farnborough, indicated the sound spectrum of engine vibrations over a range $6-4,000$ c./sec., covered in six octave bands. The scan for the six-channel bands is arranged to take place in 1/25 sec. A pulsed ultrasonic gauge was also shown which measures the velocity and attenuation of ultrasonic waves in liquids and gases. Ultrasonic cavitation and emulsification phenomena were demonstrated by means of magnetostriction-type oscillators. An interesting feature of the Exhibition was the in. creasing use of magnetic amplifiers. A number of these were shown in the amplification of D.C. signals, for example, in recording slowly varying temperatures indicated by a thermocouple. In another example the magnetic amplifier was used to operate at audiofrequencies. The germanium triode oscillator and amplifier, or transistor as it is called by the Bell Telephone Laboratories of the United States, was exhibited. It consists of a small block of germanium with two fine rectifier points placed close together on the surface, so that there is a transfer resistance between them. The input impedance is about 200 400 ohms, the output impedance being about $20,000 \mathrm{ohms}$, and power gains of the order of $20 \mathrm{~d} . \mathrm{b}$. can be obtained.

Owing to supply and other difficulties in the use of natural quartz for oscillator and resonator plates in telecommunications, synthetic quartz crystals are being developed. These are grown by a hydrothermal process using a natural quartz plate as a 'seed' crystal. In the atomic and nuclear field, electronic counters for use with Geiger-Müller tubes were shown to be capable of counting-speeds of the order of 10,000 per minute. A very interesting display of nuclear track photomicrographs was on view, the work having been done by Messrs. Kodak, Ltd., for the Atomic Energy Research Establishment at Harwell. Such a high sensitivity has been reached that the plates will record charged particles of very low ionizing power. Prof. O. R. Frisch demonstrated the application of a pulse sorter to the study of the energy distribution of particles resulting from nuclear disintegration. Each pulse causes a small steel ball to be propelled along an inclined plane with an initial speed depending on the size of the pulse. Each ball described a curved path and lands in one of thirty parallel grooves depending on the pulse height. The balls accumulating in the grooves form a histogram of the energy distribution.

These are but a few items selected almost at random from a most impressive display of modern scientific instruments. The Exhibition as a whole reflected a very healthy state of the industry. As in previous years, an exhibitors' meeting was held during the Exhibition to consider possible improvements in the organisation of future exhibitions. An important feature of the Exhibition which must be mentioned was the revival of the craftsmanship competition, arranged for youths in workshops and drawing offices in universities, research laboratories and in industry to submit specimens of their work. Some very fine examples of instrument construction and design were shown. It is to be hoped that the Physical Society will continue to encourage this feature of the Exhibition, as the future of the scientific instrument industry depends on high-quality craftsmanship.

The industry and the world at large owes a debt of gratitude to the Physical Society for the organisation of this valuable exhibition.

A. B. WoOD

\section{OBITUARIES}

Dr. Vladimir Tchernavin

top

Dr. Vladimir Tohernavin, born in Tsarskoe Selo in 1887, had lived ipokreat Britain pursuing his researches on fishes giflce 1934. He was a man willing to sacrifice more or his ideals of liberty and truth than most of At the age of twelve, on account of ill-health 7 was sent from St. Petersburg to his grandmother at Omsk; all ailments vanished at Omsk, Carid the boy and his cousin spent long days nome nomic tribes of the Siberian plains. The freedom and gaiety of the simple lives of these people made a permanent impression on young Tchernavin, which must have been reinforced as he grew to manhood by the liberal ideas that inspired the revolution of 1905. No wonder that after twelve years of service to the Soviet State he was accused in 1930 of "unproletarian psychology". His arrest was one of many that followed the failure of the first five-year plan, and he spent the next two years in a G.P.U. concentration camp.

Tchernavin's training in biology began informally, and at the age of eighteen he accompanied an expedition to western Mongolia as zoological collector. He travelled later as zoologist or fishery investigator in Mongolia, the Caspian region, Tian Shan, Bessarabia and the Far East. His early interest in fishes was centred upon the life-history of salmon, and he obtained his doctorate in ichthyology for work on structural changes in the salmon during its breeding migration.

Under the Soviets, Tchernavin lectured at the Agronomical Institute in Leningrad, and was later employed in administering the great fishery organisations of the Caspian and Murmansk. He spent long periods working under the rigorous conditions of the northern port. During his imprisonment, he was again em. ployed in fishery work, in the organisations run by the G.P.U. His behaviour at this time was designed to gain the confidence of his gaolers, who gradually allowed him more liberty of movement. At last he was able to arrange to be sent on a fishery project to a place where he had arranged to meet his wife and little boy, and with them he escaped over the mountains into Finland. During this journey the experience gained in expeditions to wild places stood him in good stead. In Finland he wrote an account of his arrest and imprisonment, and Mrs. Tehernavin described the escape. These books, entitled "I Speak for the Silent" and "Escape from the Soviets", were translated into several languages.

At the outbreak of war in 1914, Tchernavin had been on holiday in London. He had hurried to Russia for mobilization, but retained such a favourable impres. sion of London that after his escape it was here that he determined to settle. This he was enabled to do by the Academic Assistance Board (later the Society for the Protection of Science and Learning). With a grant from this organisation he returned to his beloved salmon work, perforce neglected for so many years, and published a series of papers on the lifehistory of salmon, demonstrating the nature of the changes in the skull during the breeding migration and the connexion between the magnitude of the changes and the size of the fish. Some of this had already been published in Russian during 1918-23, in journals unobtainable in Britain; but the whole was done again, with additional material and a more mature approach, and established Tchernavin as a research worker of high standard. 